\title{
Effects of evolution on egg development time
}

\author{
Andrew Hirst ${ }^{1, *}$, Angel López-Urrutia ${ }^{2}$ \\ ${ }^{1}$ British Antarctic Survey, Natural Environment Research Council, High Cross, Madingley Road, Cambridge CB3 0ET, UK \\ ${ }^{2}$ Centro Oceanográfico de Gijón, Instituto Español de Oceanografía, Avda. Príncipe de Asturias 70 bis, 33212 Gijón, \\ Asturias, Spain
}

\begin{abstract}
Using a global data set on egg hatch times in zooplanktonic and nektonic ectotherms from marine waters, the combined effects of body size, temperature and life-history attributes on development times were examined. After correcting for mass and temperature the mean egg hatch times (from laying to hatching) were 20 times faster in some taxa than in others. Some of the divergence in hatch times can be accounted for by the disposition strategy of the eggs. Eggs that are protected after laying (e.g. carried by the female, or attached to a substrate or floating in clumped masses) take 3.3 times longer on average to develop to hatching than those spawned individually and freely into the pelagic environment (i.e. 'unprotected'), and this difference is independent of egg size. Given that unprotected eggs typically have higher mortality rates, it is proposed that evolution has acted to shorten this vulnerable period. Not only do hatch times appear to diverge on the basis of egg protection strategy, but also a similar degree of separation was apparent in cell cycle duration (i.e. time from 2 to 4 cell stage). These results reinforce the importance of egg disposition on development rate processes and their evolution.
\end{abstract}

KEY WORDS: Development $\cdot$ Evolution hatch $\cdot$ Eggs $\cdot$ Metabolic theory $\cdot$ Biochemical kinetics · Zooplankton · Nekton

\section{INTRODUCTION}

Body size and temperature impose important constraints on the physiology and life-history parameters of organisms. The theoretical basis for such powerful constraints has been subject to much debate, with interest renewed by the development of the metabolic theory of ecology, which extends to a vast diversity of fields from the scaling of organism metabolism and development times, to the flux rates within ecosystems (see Brown et al. 2004). At the base of this theoretical framework are those processes that control chemical reactions within cells, and the designs of resource distribution networks. A description of development times by Gillooly et al. (2002) suggested that egg hatch and egg-to-adult development time $(t)$ across a diverse grouping of animals can be described by:

$$
t=m^{1 / 4} \frac{4}{a\left(T_{0}\right) \mathrm{e}^{\left(\bar{E} / k T_{0}^{2}\right)\left\{T_{C} /\left[T_{C} / T_{0}\right]\right\}}}
$$

where $m$ is body mass, $T_{C}$ is temperature $\left({ }^{\circ} \mathrm{C}\right), \bar{E}$ is the average activation energy for metabolic reaction, $k$ is Boltzmann's factor, $T_{0}$ is 273 (setting Kelvin to $0^{\circ} \mathrm{C}$ ), and $a\left(T_{0}\right)$ is a normalisation factor for development, which is independent of body size and temperature. The normalisation factor and hence the intercept $\left(y_{\text {int }}\right)$ of the relationship between mass-corrected development time $\left(\ln \left[t / m^{1 / 4}\right]\right)$ and temperature $\left(T_{C} /\left[1+T_{C} / T_{0}\right]\right)$ is variable across taxa $\left(y_{\text {int }}=\ln \left[4 / a\left(T_{0}\right)\right]\right)$ (Gillooly et al. 2002, Lopez-Urrutia 2003), and this variability should be central in examining the effects of biotic and abiotic factors on body mass- and temperature-corrected development times (Brown et al. 2004). Of the many possible factors that can affect mass- and temperaturecorrected development times, life-history optimisation models of egg-to-maturation time often have mortality and growth rates as central predictive parameters (Stearns \& Crandall 1981, Roff 1984). According to many life-history models, if mortality or growth rates 
are altered, development times can adapt or evolve. Direct experimental evidence to support this is provided by the modification of development times by mortality schedules (e.g. Reznick et al. 1990) or predation cues (Dodson \& Havel 1988, Macháček 1993). These models, however, have generally not been used to examine or explain patterns across taxa or with respect to temperature and body mass scaling, although these inter-specific patterns are known to be distinct.

Eggs comprise a critical stage in the life-history of many organisms, and they are often subject to high mortality rates. The time from egg-laying to hatching (egg hatch time) dictates the period over which organisms experience these high mortality rates. The eggs of marine planktonic copepods that are freely spawned have higher mortality rates than those species in which the female carries the eggs until hatching. In the latter case the female actively avoids predation (for example by escape responses and/or diel migration), and consequently egg mortality is largely coupled to that of the female, and can be 1 order of magnitude less than mortality of freely spawned eggs (Kiørboe 1998, Hirst \& Kiørboe 2002). Eggs attached to substrate or in floating clumped masses would be expected to be less vulnerable. Benthic deposited eggs often receive parental care, or possess protective gels, or tough envelopes, whereas free pelagic eggs are often considered the most vulnerable embryos of marine animals (Staver \& Strathmann 2002). Mortality rates in the plankton may be higher than those of protected benthic embryos (Strathmann 1985, Rumrill 1990). Should evolution reduce the development time of highly vulnerable stages, we would expect discernible differences in development time between unprotected (free planktonic) eggs and protected eggs (carried by the female, attached to substrates or aggregated into masses). Kiørboe \& Sabatini (1994) found in marine pelagic copepods that freely spawned eggs took around one third of the time to hatch than that of eggs carried by the female. They suggested that this was a consequence of higher mortality rates of the freely spawned eggs, and that fast hatching was a means of escaping predators. In this study, we give special attention to egg hatch times because these are both central to Gillooly et al.'s (2002) model of development and because they can encompass radically different mortality rates and environments in which they are laid.

This study compiles development times from a diverse range of epi-pelagic marine ectotherms (zooplankton and nekton), and uses these data to examine differences in development rates between different taxa with different characteristics of egg disposition. Specifically we address the questions: (1) To what extent are the intercepts of mass-corrected egg hatch versus temperature different for different taxa? (2) Do freely spawned pelagic eggs have different hatch times from those which are offered protection in some way?

\section{METHODS}

Data compilation. We first examined the literature for development times of eggs, from laying to hatching, in marine epi-pelagic zooplankton and nekton. For some taxa such data have already been carefully screened and compiled. For marine planktonic copepods we used the data sets of Hirst \& Bunker (2003) on broadcast-spawning and egg carrying copepods, for pelagic marine fish eggs the data set of Pauly \& Pullin (1988) on hatching times, and for mysids the marine and brackish epipelagic data of Wittmann (1984), which represents marsupial development, i.e. the time from egg laying to the point of release from the brood pouch. We corrected the latter to egg hatch time by multiplying marsupial development time by 0.325 , the mid-point of the range $(0.25$ to 0.40) in the original study (Wittmann 1984). We included the marine component of the data compiled by Gillooly et al. (2002) on fish egg hatch times. Appendicularian, euphausiid, cephalopod and chaetognath egg hatch times were taken from published sources. All data are available upon request from the authors. We included the temperature at which the measurements were made. We compared data between taxa, but also within each taxon we separated data on the basis of egg disposition strategy. Data for eggs that are freely spawned individually into the water column (termed 'unprotected') were distinguished from 'protected' eggs, i.e. eggs that are attached to the female until hatching, those attached to substrates, and those laid in clumped egg masses. Eggs carried by the female, or laid in aggregates attached to substrates (e.g. on macroalgae, under rocks, or on the seafloor) should be more protected than eggs freely spawned into the pelagic environment. When diameters were given for different axes of the eggs, we calculated the mean and converted this to a volume using the equation for a sphere. Volumes of eggs were converted to wet mass assuming a density of $1 \mathrm{~g} \mathrm{ml}^{-3}$; wet mass values ( $\mathrm{g}$ ) were used for mass-corrected egg development times (see Fig. 1). Carbon masses were also derived for comparison. Whenever possible, taxon-specific conversions were used. Many of the data sets contain more than one data point per species (e.g. Pauly \& Pullin 1988, Hirst \& Bunker 2003), and similarly to Gillooly et al. (2002) we did not compress these data sets. The appendicularian and chaetognath data set on egg hatch times comprised only 2 and 3 species respectively. The vast majority of data included here are from laboratory studies on egg hatch time, with temperature controlled and held constant through the incubation. The data of Pauly \& Pullin (1988) for fish eggs consists of around one-third 


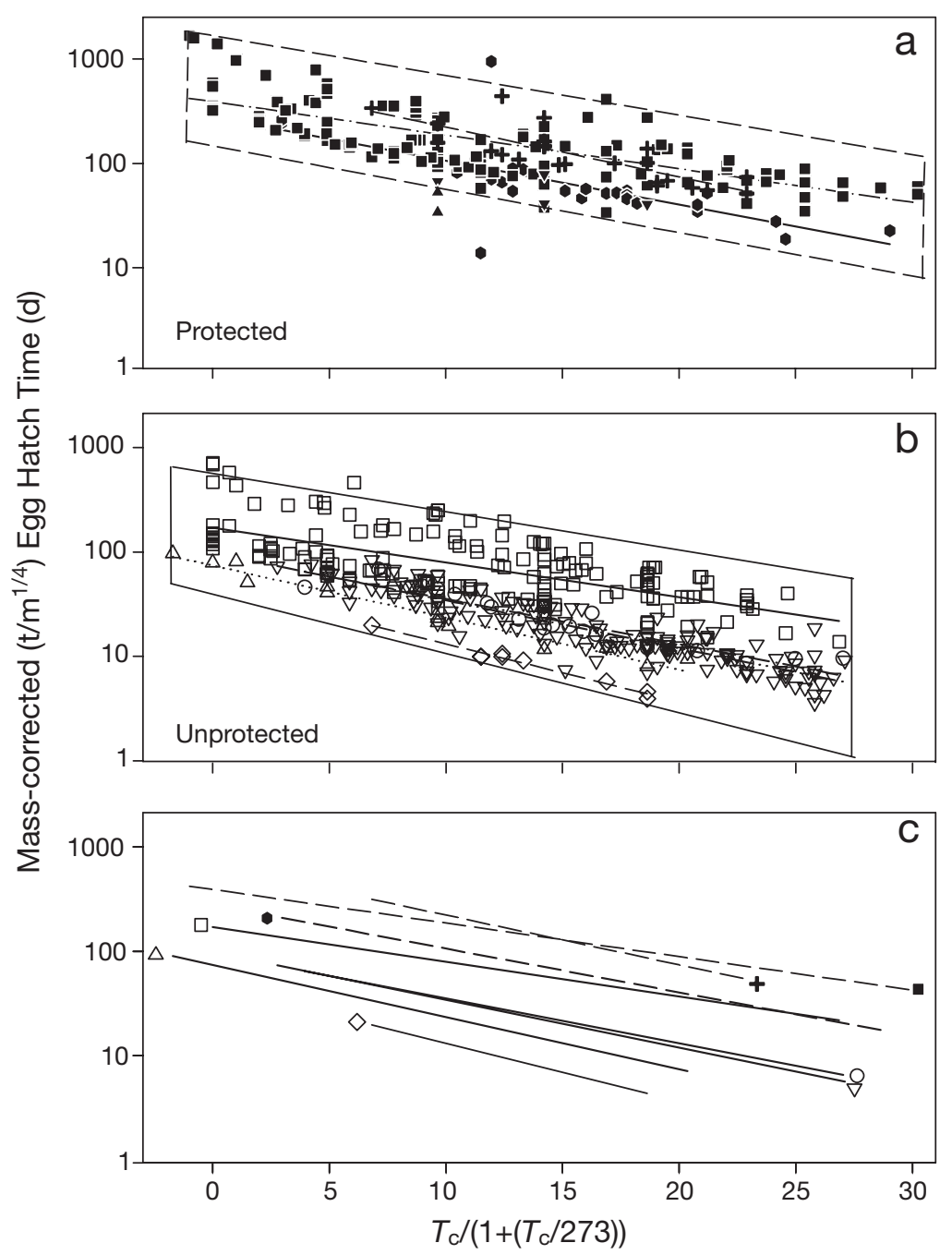

\begin{tabular}{|lc|}
\hline Unprotected Eggs & Protected Eggs \\
$-\checkmark$ Appendicularians & -- Copepods \\
$-\odot$ Chaetognaths & - - Mysids \\
$\square-$ Copepods & - Euphausiids \\
$\cdots \triangle$ Euphausiids & $\checkmark$ Fish \\
$-\nabla-$ Fish & + Cephalopods \\
\hline
\end{tabular}

Fig. 1. Mass-corrected development time as a function of temperature $\left(T_{C} /\left[1+\left(T_{c} / 273\right)\right]\right)$. Time from laying to hatching for eggs that are (a) protected (either carried by adult until hatching, laid in egg masses and/or attached to substrates), and (b) unprotected (freely spawned individually into the pelagic environment); envelopes around data (drawn by eye) encompass $>95 \%$ of data points. (c) Regression lines for all taxa in each of the egg disposition groups (continuous lines $=$ unprotected eggs; dashed lines = protected eggs; symbols denote taxon); regressions through data for protected eggs of euphausiids and fishes not undertaken since too few data ( $\mathrm{n}=2$ and 6 , respectively); also data for protected eggs of euphausiids are only at $10^{\circ} \mathrm{C}$. All mass correction is to wet mass ( $\mathrm{g}$ ) following protocol of Gillooly et al. (2002); all regressions

obtained by ordinary least-squares method

field data, but there was no significant difference between laboratory and field results in their study (D. Pauly, pers. comm.).

Data analysis. We used ordinary least-squares (OLS) regressions between $\log _{\mathrm{e}}$ mass-corrected developmental times and temperature. This regression technique was justified for egg hatching times, since most data were from laboratory studies in which temperature was controlled. When this parameter is not controlled, a reduced major axis regression (RMA) is recommended. However, preliminary analysis of our data set (after McArdle (1988), assuming that the size of error in x-values was unlikely to exceed 4 to $5^{\circ} \mathrm{C}$ ), using the RMA method underestimated the true slope much more than OLS overestimated it. We therefore considered OLS to provide more accurate results, and henceforth applied this method to our data. Regressions through the data for the protected eggs of euphausiids and fishes were not computed because of lack of sufficient data ( $\mathrm{n}=2$ and 6, respectively); also, in the case of the euphausiids hatch times were available for only one temperature, $10^{\circ} \mathrm{C}$.

\section{RESULTS}

Mass-corrected egg hatch times were strongly correlated with temperature (Fig. 1), with $\mathrm{p}<0.001$. Slopes of $\log _{\mathrm{e}}$ mass-corrected egg hatch times versus temperature (as $T_{C} /\left[1+\left(T_{C} / 273\right)\right]$, where $T_{C}$ is temperature in ${ }^{\circ} \mathrm{C}$ ), varied from -0.074 to -0.127 (Table 1 ). Intercepts of these relationships varied dramatically (3.8 to 6.5) between different taxonomic groups. At $19^{\circ} \mathrm{C}$ mass-corrected egg hatch times for carried eggs of copepods were 20 times longer than those for appendicularian eggs.

Egg hatch times were corrected to a temperature of $15^{\circ} \mathrm{C}$ using an average activation energy of 0.65 (Gillooly et al. 2002), and are compared on the basis of egg mass and volume in Fig. 2. There are obvious differences between taxa. To a large degree these 
Table 1. Mass-corrected egg hatch $\left[\mathrm{d} /(\mathrm{g} \text { wet mass })^{1 / 4}\right]$ times in a variety of pelagic organisms in relation to temperature, all results presented are from regressions using Ordinary Least-Squares. Relationships for the protected eggs of euphausiids and fishes are not included since data are too few ( $n=2$ and 6 respectively). N: number of data points. $p<0.001$ in all cases

\begin{tabular}{|c|c|c|c|c|c|c|}
\hline Category & $\mathrm{n}$ & $\begin{array}{l}\text { Temperature } \\
\text { range }\left({ }^{\circ} \mathrm{C}\right)\end{array}$ & $\begin{array}{l}\log _{e} t=a \\
a(S E)\end{array}$ & $\begin{array}{c}T_{c} /\left[1+\left(T_{c} / 273\right)\right. \\
\text { b (SE) }\end{array}$ & $+b$ & Source \\
\hline \multicolumn{7}{|c|}{ Unprotected eggs (broadcast spawners) } \\
\hline Copepods & 167 & 0.0 to 29.8 & $-0.077(0.0065)$ & $5.141(0.085)$ & 0.455 & Hirst \& Bunker (2003) \\
\hline Appendicularians & 9 & 7.0 to 20.0 & $-0.127(0.0074)$ & $3.849(0.104)$ & 0.977 & This study \\
\hline Chaetognaths & 22 & 4.0 to 30.0 & $-0.099(0.0079)$ & $4.560(0.126)$ & 0.888 & This study \\
\hline Euphausiids & 15 & -1.7 to 22.0 & $-0.115(0.0065)$ & $4.303(0.072)$ & 0.966 & This study \\
\hline Fish & 140 & 2.8 to 30.1 & $-0.105(0.0042)$ & $4.588(0.074)$ & 0.822 & Pauly \& Pullin (1988) \\
\hline \multicolumn{7}{|l|}{ Protected eggs } \\
\hline Copepods (egg-carrying) & 167 & -1.0 to 34.0 & $-0.074(0.0052)$ & $5.968(0.072)$ & 0.556 & Hirst \& Bunker (2003) \\
\hline $\begin{array}{l}\text { Cephalopods (eggs in masses } \\
\text { or attached to substrate) }\end{array}$ & 24 & 7.0 to 25.0 & $-0.110(0.0161)$ & $6.499(0.260)$ & 0.677 & This study \\
\hline Mysids (egg-carrying) & 29 & 3.0 to 32.5 & $-0.096(0.0205)$ & $5.629(0.347)$ & 0.451 & Wittmann (1984) \\
\hline
\end{tabular}

differences were related to whether the eggs fall into protected or unprotected groups. Unprotected eggs have significantly shorter hatch times than protected eggs of similar size. We calculated the geometric mean temperature-corrected development time and egg size for each taxon within the protected and unprotected groups and then regressed the values for each of the 2 protections categories separately. The regressions demonstrate that protected eggs take \%3.3 times longer to hatch than unprotected eggs, and that this difference is independent of egg size (the slopes are parallel). Differences in hatch times are discernible not only between different taxa, but also within taxa that employ both strategies. In the Copepoda for example, eggs that are freely broadcasted develop $\sim 2.4$ times faster than eggs that are carried by the female (ANCOVA, p for differences of slope $=0.772$ and intercept $<0.001)$. Marine fish eggs attached to substrates typically take longer to develop to hatching than those that are freely spawned (see Discussion). Regressions through the geometric mean values for protected and unprotected eggs have slopes between 0.25 and 0.26 (Fig. 2), confirming the across-taxa scaling of mass ${ }^{0.25}$ used to correct for body mass both here and in Gillooly et al. (2002). The within-taxa scaling relationship (e.g. the scaling of broadcast copepod eggs) differs from the general between-taxa scaling relationship, however (see Fig. 2).

The variability in egg hatch times accounted for by mass and temperature is $41 \%$ for the data set as a whole, while regressions for egg hatch times that are taxon and life-history specific (e.g. broadcastspawning copepods) account for $>67 \%$ of the variability in all but one case.

\section{DISCUSSION}

One striking feature of our compilation and analysis of egg development times, which includes a wide range of marine epi-pelagic organisms, is that differences in intercepts between egg hatch times of different taxa can to some extent be explained by egg disposition strategy. A similar observation was made by Kiørboe \& Sabatini (1994) on marine pelagic copepods; in this study we have been able to demonstrate these differences across a wider range of taxa and protection strategies. Eggs that are spawned individually and freely into the pelagic environment (unprotected) generally hatch much more quickly than eggs that are carried by the female, attached to substrates, or spawned in egg-masses (all of these strategies may afford a greater degree of protection) (Fig. 2). On average we found that protected eggs take $\sim 3.3$ times longer to hatch than unprotected eggs, and that this difference is independent of egg size (slopes are parallel). These findings are very similar to the difference in hatch times found for marine pelagic copepods, with carried eggs taking $\sim 3$ times longer to hatch than freely spawned eggs (Kiørboe \& Sabatini 1994). Although the data for the protected and unprotected groups overlap, there are still considerable differences for most taxa. Longer development time may enable hatching of more advanced development stages with greater abilities to detect and avoid their predators. However, such advantage is counterbalanced by increased mortality arising from longer exposure to predation risk. In protected and unprotected eggs the optimal trade-off between these 2 factors is radically different. Differences in hatching time between protected and unprotected 


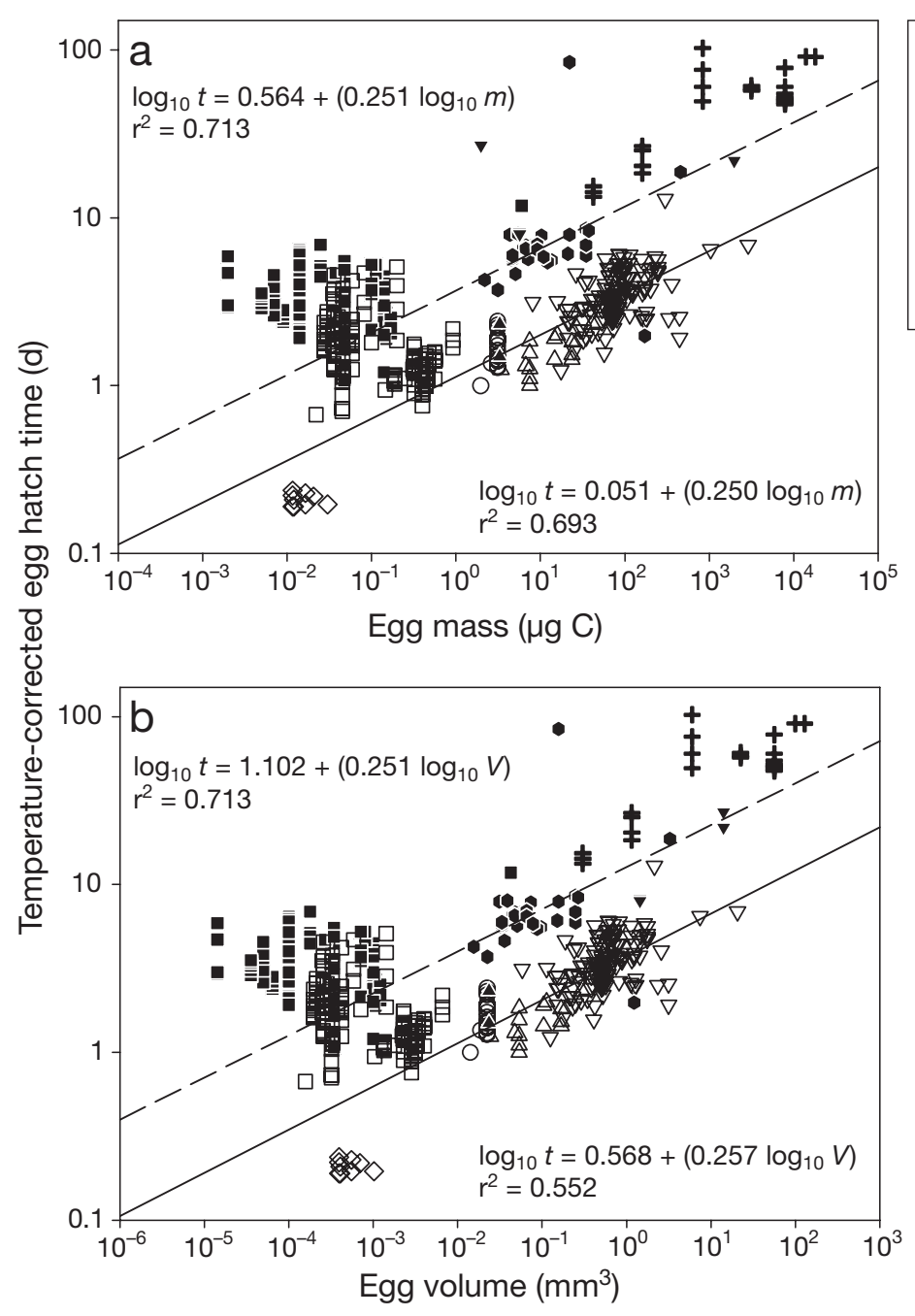

\begin{tabular}{|lr|}
\hline Unprotected Eggs & Protected Eggs \\
$\diamond$ Appendicularians & - Copepods \\
$\bigcirc$ Chaetognaths & - Euphausiids \\
$\square$ Copepods & - Fish eggs \\
$\triangle$ Euphausiids & Mysids \\
$\nabla$ Fish eggs & + Cephalopods \\
Regression through & -- Regression through \\
taxa geometric means & taxa geometric means \\
\hline
\end{tabular}

Fig. 2. Egg hatch time vs. (a) egg carbon mass and (b) egg volume. All data corrected to $15^{\circ} \mathrm{C}$ using average activation energy value of 0.65 (Gillooly et al. 2002), and divided into egg disposition category described in Fig. 1 legend. Continuous regression line = unprotected eggs; dashed regression line $=$ protected eggs. Regressions performed on geometric mean taxa values within each of the egg protection strategies. Equations for unprotected eggs: $\log _{10} t=0.568+\left(0.257 \log _{10}\right.$ $V)$ (where $V$ is volume in $\left.\mathrm{mm}^{3}\right)\left(\mathrm{r}^{2}=0.552\right), \log _{10} t=$ $0.051+\left(0.250 \log _{10} m\right)(m$ is carbon mass, $\mu \mathrm{g} C)\left(r^{2}=\right.$ $0.693)$. Equations for protected eggs: $\log _{10} t=1.102+$ $\left(0.251 \log _{10} V\right)\left(\mathrm{r}^{2}=0.713\right), \log _{10} t=0.564+\left(0.251 \log _{10}\right.$ m) $\left(\mathrm{r}^{2}=0.713\right)$. All regression obtained by OLS method eggs suggest that development times are evolvable, non-conservative characteristics.

The range in mass-corrected egg hatch times at any temperature is much lower when the protected and unprotected groups are considered separately (usually $<1$ order of magnitude difference at any temperature). Using the approach of Gillooly et al. (2002) for our more taxonomically diverse compilation of marine zooplankton data indicated that only $41 \%$ of the variation in egg development time was accounted for by temperature and body size alone (i.e. disregarding taxonomic division). Dividing our data set simply into protected and unprotected groups indicated that temperature and mass explained 52 and $57 \%$ of the variability in these 2 groups, respectively. This is a reasonable improvement over results achieved ignoring the role of egg protection, especially considering that we divided data using a simple classification scheme. Use of more quantitative criteria, such as mortality rates and other life-history attributes, might achieve greater improvements.
Our analysis revealed that intercepts vary between taxa. Mass-corrected egg hatch times of the carried eggs of copepods are 20 times longer than those of appendicularians at $19^{\circ} \mathrm{C}$ (although the appendicularian data is poor in species, with 9 of the 10 data points being from Oikopleura dioica). This difference is greater than that for the temperature extremes ( -1 and $34^{\circ} \mathrm{C}$ ) of the regression line for egg carrying copepods. Thus, the differences between taxa at any one temperature can be greater than the differences within taxa across the full range of (global ocean) temperatures experienced. Intercepts for the range of taxa examined varied from 3.8 to $>6$, representing differences in egg hatch times at $0^{\circ} \mathrm{C}$ ranging over 1 order of magnitude.

Differences in hatch times between protected and unprotected eggs are also discernible for other development rate measurements. The time embryos require to pass from the 2 cell to the 4 cell phase (a cell cycle time) was measured by Strathmann et al. (2002) for a range of aquatic organisms (Echinodermata, 


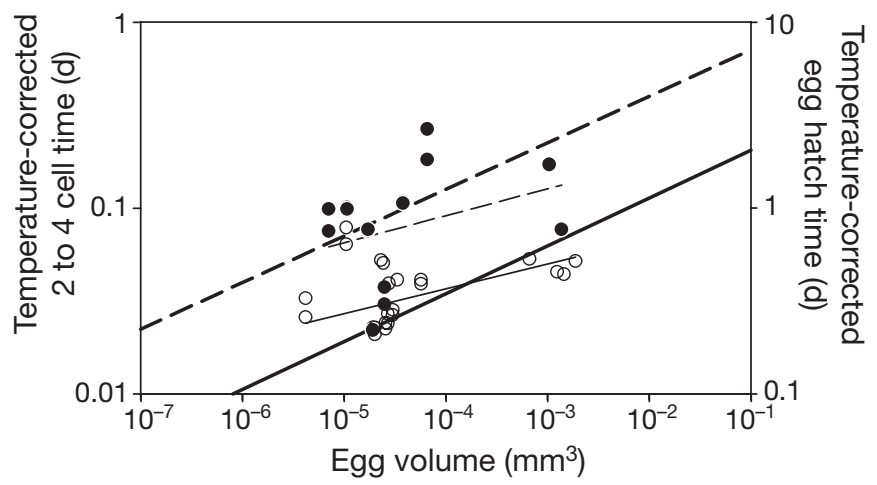

- Protected Eggs - Time from 2 to 4 cells
- Unprotected Eggs - Time from 2 to 4 cells
- - Protected Eggs - Development Time
- Unprotected Eggs - Development Time

Fig. 3. Time for fertilised egg embryos to pass from 2 to 4 cell stage versus egg volume. Data from Strathmann et al. (2002) comprising data from taxa Echinodermata, Mollusca, Phoronida, Brachiopoda and Chordata. All data corrected to $15^{\circ} \mathrm{C}$ using average activation energy value of 0.65 (Gillooly et al. 2002). Species divided into egg disposition categories described in Fig. 1 legend. For comparative purposes regressions for egg hatch times vs. egg volume from our Fig. 2b are given by heavy lines (scale given on right-hand axis; note change in scale in comparison to left-hand axis). All regressions obtained by OLS method

Mollusca, Phoronida, Brachiopoda and Chordata). They observed that embryos at low risk had slower development rates (measured as the time from first to second cleavage of the egg). Strathmann et al. (2002) also considered aggregated and brooded eggs to be less vulnerable. In Fig. 3 we correct their cell cycle times to $15^{\circ} \mathrm{C}$ using an average activation energy of 0.65 (Gillooly et al. 2002), and compare the relationship with egg volume with the relationship we found for egg hatch times. These egg development measurements (2 to 4 cell cycle times) again diverge on the basis of being protected or unprotected, with the latter taking around 2.6 times as long to pass from 2 to 4 cells.

Gillooly et al. (2002) suggest that the data for freely spawned marine pelagic fish eggs from Pauly \& Pullin (1988) have a similar slope and intercept to data they compiled from laboratory studies. However, LopezUrrutia (2003) later showed that the intercept of the laboratory data of Gillooly et al. (2002) for fishes (with an intercept of 4.59) is much lower than that of Pauly \& Pullin (1988) (with an intercept of 5.73). At $15^{\circ} \mathrm{C}$ egg hatch time was $44 \mathrm{~d}$ in Gillooly et al.'s laboratory data, but only $22 \mathrm{~d}$ in the marine pelagic eggs from Pauly \& Pullin. We re-examined this difference from the perspective of egg protection strategies. Gillooly et al.'s (2002) data set on fish eggs hatched under laboratory conditions was dominated by freshwater species, in- cluding many which lay their eggs in the protected environment of benthic redds, i.e. gravel nests (33 of their 56 data points). In Fig. 4 we compare this specific sub-set with marine broadcast fish eggs. Again the results do appear to diverge on the basis of degree of protection, with the eggs laid in protected redds having longer hatch times than the vulnerable free pelagic eggs. Given the great differences between fresh and marine waters, other reasons for these differences cannot be discounted at this stage. Nonetheless, we suggest that protection strategies are important and impact egg hatch times between environment types, and not simply within the marine environment.

Strathmann et al. (2002) compared time to first locomotion in embryos of asteroids, gastropods, phoronids, and brachiopods, and found that unprotected embryos initiated locomotion at both an earlier stage and younger age than protected benthic embryos. Furthermore, structures in the first swimming stage are generally less developed in pelagic spawned eggs than in eggs that are brooded or deposited in egg masses (Strathmann 1987, Kiørboe \& Sabatini 1994, Satoh 1994, Strathmann et al. 2002). As pointed out by Strathmann et al. (2002), time to hatching combines rate of development and stage at hatching in a single measurement. Hatchlings in different taxa can be in radically different states of development. Thus, when comparing time to egg hatch between different taxa one may not be making comparisons across equal stages of development. The time of hatching cannot therefore be regarded as a point of constant developmental state; rather it is a measure of different degrees of development in different taxa, with different numbers of cell cycles and different numbers of cells in the embryo. Thus, different rates of development (Fig. 3)

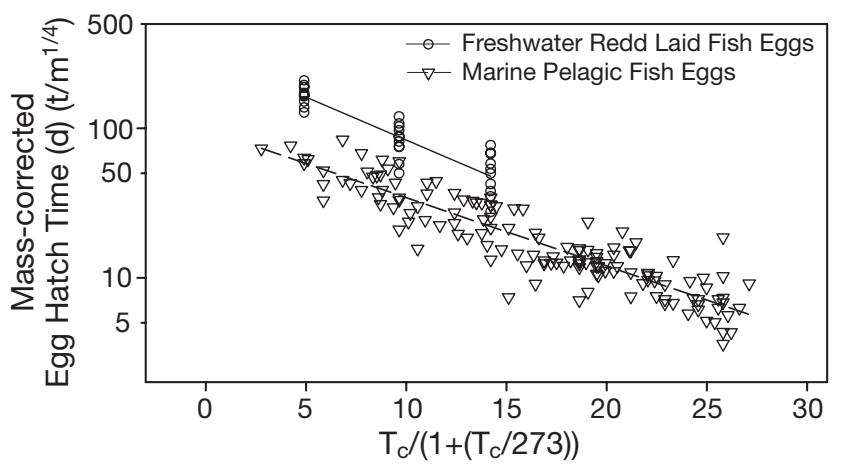

Fig. 4. Mass-corrected development time as a function of temperature $\left(T_{C} /\left[1+\left(T_{C} / 273\right)\right]\right)$ from egg laying to hatching for marine pelagic broadcast eggs (data from Pauly \& Pullin 1988), and freshwater eggs that are laid in redds (data from Gillooly et al. 2002). All mass correction is to wet mass ( $\mathrm{g}$ ) following protocol of Gillooly et al. (2002). All regressions obtained by OLS method 
and different degrees of development at hatch in eggs with different protection strategies may both explain the markedly different rates in egg hatch times between different taxa. Models of egg (and egg to adult) development need to consider the large scale patterns that are in evidence, but also the differences between taxa and egg protection strategies, if in future they are to capture more adequately the emerging patterns.

Acknowledgements. This work is part of the BAS DISCOVERY 2010 Programme, and the NERC Marine Productivity Thematic Programme (Grant Ref. NE/C508418/1 to A.G.H). The work of A.L.-U. was partially funded by a FICYT grant under the Marco del Plan de Investigacion, Desarrollo Tecnologico e Innovacion de Asturias 2001 to 2004. We wish to thank David Atkinson, Andrew Clarke and Jose Luis Acuña for their invaluable comments. Pete Rothery provided statistical advice. The comments of R. Strathmann, T. Kiørboe and anonymous reviewers greatly improved the work.

\section{LITERATURE CITED}

Brown JH, Gillooly JF, Allen AP, Savage VM, West GB (2004) Towards a metabolic theory of ecology. Ecology 85: 1771-1789

Dodson SI, Havel JH (1988) Indirect prey effects: some morphological and life history responses of Daphnia pulex exposed to Notonecta undulata. Limnol Oceanogr 33: $1274-1285$

Gillooly JF, Charnov EL, West GB, Savage VM, Brown JH (2002) Effects of size and temperature on development time. Nature 417:70-73

Gillooly JF, Charnov EL, Brown JH, Savage VM, West GB (2003) Reply. Nature 424:270

Hirst AG, Bunker AJ (2003) Growth of marine planktonic copepods: global rates and patterns in relation to chlorophyll a, temperature, and body weight. Limnol Oceanogr 48:1988-2010

Editorial responsibility: Otto Kinne (Editor-in-Chief), Oldendorf/Luhe, Germany
Hirst AG, Kiørboe T (2002) Mortality in marine planktonic copepods: global rates and patterns. Mar Ecol Prog Ser 230:195-209

Kiørboe T (1998) Population regulation and role of mesozooplankton in shaping marine pelagic food webs. Hydrobiologia 363:13-27

Kiørboe T, Sabatini M (1994) Reproductive and life cycle strategies in egg-carrying cyclopoid and free-spawning calanoid copepods. J Plankton Res 16:1353-1366

López-Urrutia A (2003) How reliable is the biological time clock? Nature 424:269-270

Macháček J (1993) Comparison of the response of Daphnia galeata and Daphnia obtuse to fish-produced chemical substances. Limnol Oceanogr 38:1544-1550

McArdle BH (1988) The structural relationship: regression in biology. Can J Zool 66:2329-2339

Pauly D, Pullin RSV (1988) Hatching time in spherical, pelagic, marine fish eggs in response to temperature and egg size. Environ Biol Fish 22:261-271

Reznick DA, Bryga H, Endler JA (1990) Experimentally induced life-history evolution in a natural population. Nature 346:357-359

Roff DA (1984) The evolution of life history parameters in teleosts. Can J Fish Aquat Sci 41:989-1000

Rumrill SS (1990) Natural mortality of marine larvae. Ophelia 32:163-198

Staver JM, Strathmann RR (2002) Evolution of fast development of planktonic embryos to early swimming. Biol Bull 203:58-69

Stearns SC, Crandall RE (1981) Quantitative predictions of delayed maturity. Evolution 35:455-463

Strathmann MF (1987) Reproduction and development of marine invertebrates of the northern Pacific coast. University of Washington Press, Seattle

Strathmann RR (1985) Feeding and nonfeeding larval development and life-history evolution in marine invertebrates. Annu Rev Ecol Syst 16:413-428

Strathmann RR, Staver JM, Hoffman JR (2002) Risk and the evolution of cell-cycle durations of embryos. Evolution 56: 708-720

Wittmann KJ (1984) Ecophysiology of marsupial development and reproduction in Mysidacea (Crustacea). Oceanogr Mar Biol Annu Rev 22:393-428

Submitted: June 6, 2006; Accepted: July 5, 2006

Proofs received from author(s): October 19, 2006 